\title{
Effects of fish oil supplement on psoriasis: a meta-analysis of randomized controlled trials
}

\author{
Shih-Jyun Yang ${ }^{1,2}$ and Ching-Chi $\mathrm{Chi}^{2,3^{*}}$ (D)
}

\begin{abstract}
Background: Fish oils, which contain omega-3 polyunsaturated fatty acids as the active ingredients, possess antiinflammatory activities and may have therapeutic potential in diseases with an inflammatory etiology. Fish oil supplement has been advocated for treating psoriasis which is a chronic inflammatory dermatosis.
\end{abstract}

Objective: We aimed to investigate the effects of fish oil supplement on psoriasis.

Methods: We searched CENTRAL, Embase and MEDLINE on 24 January 2018 for randomized control trials (RCTs) on the effects of fish oil supplement in treating psoriasis. The Cochrane Collaboration's tool was used to assess the risk of bias of included RCTs. We performed a random-effects model meta-analysis to obtain the pooled treatment effect estimates.

Results: We included 13 RCTs with 625 participants. Three RCTs involving 337 participants provided usable data for meta-analysis. Fish oil supplement did not significantly reduce the severity of psoriasis when assessed by Psoriasis Area and Severity Index score (mean difference - 0.28; 95\% confidence interval - 1.74 to 1.19).

Conclusion: The current evidence does not support the use of fish oil supplement in treating psoriasis.

Key words: Fish oil, Meta-analysis, Polyunsaturated fatty acids, Psoriasis, Systematic review

\section{Background}

Psoriasis is a chronic inflammatory dermatosis characterized by well-demarcated erythematous plaques with silvery scales $[1,2]$. Although the hallmark clinical feature is the cutaneous manifestation, psoriasis has increasingly been recognized as a systemic inflammatory disorder with comorbidities including arthritis [3], cardiometabolic disease [4], uveitis [5], and chronic kidney disease [6]. Psoriasis has substantial negative impact on affected patient's quality of life [7].

One question frequently asked by psoriasis patients is whether a dietary change or supplementation with specific nutrients can improve their condition. Some studies have suggested that supplementation with fish oil, which contains omega-3 polyunsaturated fatty acids ( $\omega-3$ PUFAs) including eicosapentaenoic acid (EPA) and

\footnotetext{
* Correspondence: chingchi@cgmh.org.tw

Department of Dermatology, Chang Gung Memorial Hospital, Linkou, 5, Fuxing St, Guishan Dist, Taoyuan 33305, Taiwan

${ }^{3}$ College of Medicine, Chang Gung University, Taoyuan, Taiwan

Full list of author information is available at the end of the article
}

docosahexaenoic acid (DHA) as the active ingredients, may be beneficial in psoriasis, likely through their antiinflammatory effect [8]. However, other studies have revealed conflicting results [9]. In this study, we aimed to systemically assess the evidence on the effects of fish oil supplement in treating psoriasis.

\section{Methods}

We conducted a systematic review and meta-analysis of randomized controlled trials (RCTs) on the effects of fish oil supplement in treating psoriasis. The reporting of this study followed the Preferred Reporting Items for Systematic Reviews and Meta-Analyses (PRISMA) [10]. We searched the Cochrane Central Register of Controlled Trials (CENTRAL), Embase, and MEDLINE for relevant publications on 24 January 2018. The search strategy is listed in Table 1. Studies were included if they met all of the following eligibility criteria: (1) study design being RCTs; (2) the participants were psoriasis patients; (3) the study intervention was fish oil/ $\omega-3$ PUFAs 
Table 1 Search strategy

\begin{tabular}{|c|c|}
\hline Database & Search strategy \\
\hline $\begin{array}{l}\text { Cochrane Central Register of Controlled Trials } \\
\text { (CENTRAL) }\end{array}$ & $\begin{array}{l}\text { \#1 MeSH descriptor: [Psoriasis] explode all trees } \\
\text { \#2 Psoriasis:ti,ab,kw (Word variations have been searched) } \\
\text { \#3 \#1 or \#2 } \\
\text { \#4 MeSH descriptor: [Fish Oils] explode all trees } \\
\text { \#5 Fish Oil:ti,ab,kw (Word variations have been searched) } \\
\text { \#6 fish liver oil:ti,ab,kw (Word variations have been searched) } \\
\text { \#7 MeSH descriptor: [Cod Liver Oil] explode all trees } \\
\text { \#8 Cod Liver Oil:ti,ab,kw (Word variations have been searched) } \\
\text { \#9 MeSH descriptor: [Fatty Acids, Omega-3] explode all trees } \\
\text { \#10 Omega-3:ti,ab,kw (Word variations have been searched) } \\
\text { \#11 Omega3:ti,ab,kw (Word variations have been searched) } \\
\# 12 \text { MeSH descriptor: [Eicosapentaenoic Acid] explode all trees } \\
\# 13 \text { EPA:ti,ab,kw (Word variations have been searched) } \\
\text { \#14 eicosapentaenoic acid:ti,ab,kw (Word variations have been searched) } \\
\text { \#15 eicosapentaenoate:ti,ab,kw (Word variations have been searched) } \\
\text { \#16 icosapentaenoic acid:ti,ab,kw (Word variations have been searched) } \\
\# 17 \text { MeSH descriptor: [Docosahexaenoic Acids] explode all trees } \\
\text { \#18 DHA:ti,ab,kw (Word variations have been searched) } \\
\text { \#19 docosahexaenoic acid:ti,ab,kw (Word variations have been searched) } \\
\# 20 \text { docosahexaenoate:ti,ab,kw (Word variations have been searched) } \\
\# 21 \text { \#4 or \#5 or \#6 or \#7 or \#8 or \#9 or \#10 or \#11 or \#12 or \#13 or \#14 or \#15 or \#16 or \#17 or } \\
\# 18 \text { or \#19 or \#20 } \\
\text { \#22 \#3 and \#21 }\end{array}$ \\
\hline Embase & $\begin{array}{l}\text { \#1 'psoriasis'/exp. OR 'psoriasis' } \\
\text { \#2 'fish oil' } \\
\text { \#3 'fish liver oils' } \\
\text { \#4 'cod liver oil' } \\
\text { \#5 'omega } 3 \text { fatty acid' } \\
\text { \#6 'eicosapentaenoic acid' } \\
\text { \#7 'icosapentaenoic acid' } \\
\text { \#8 eicosapentaenoate } \\
\text { \#9 'docosahexaenoic acid' } \\
\text { \#10 docosahexaenoate } \\
\# 11 \text { \#2 OR \#3 OR \#4 OR \#5 OR \#6 OR \#7 OR \#8 OR \#9 OR \#10 } \\
\# 12 \text { \#1 AND \#11 }\end{array}$ \\
\hline MEDLINE & $\begin{array}{l}1 \text { exp Psoriasis/ } \\
2 \text { psoriasis.mp. } \\
31 \text { or } 2 \\
4 \text { exp. Fish Oils/ } \\
5 \text { fish oil.mp. } \\
6 \text { fish liver oil.mp. } \\
7 \text { exp. Cod Liver Oil/ } \\
8 \text { cod liver oil.mp. } \\
9 \text { exp. Fatty Acids, Omega-3/ } \\
10 \text { omega-3.mp. } \\
11 \text { omega3.mp. } \\
12 \text { exp. Eicosapentaenoic Acid/ } \\
13 \text { EPA.mp. } \\
14 \text { eicosapentaenoic acid.mp. } \\
15 \text { eicosapentaenoate.mp. } \\
16 \text { icosapentaenoic acid.mp. } \\
17 \text { exp. Docosahexaenoic Acids/ } \\
18 \text { DHA.mp. } \\
19 \text { docosahexaenoic acid.mp. } \\
20 \text { docosahexaenoate.mp. } \\
21 \text { or/4-20 } \\
223 \text { and } 21\end{array}$ \\
\hline
\end{tabular}

supplement and the comparator was placebo or other active treatments; and (4) published in English. Studies involving only dietary modification were excluded. Our primary outcomes included: (1) the severity of psoriasis measured by Psoriasis Area and Severity Index (PASI) score or involved body surface area (BSA) and (2) adverse events (AEs). Our secondary outcomes included:
(1) the degree of psoriasis signs including erythema (redness), scaling (desquamation), and induration (thickness/ infiltration) and (2) the degree of pruritus.

Two authors (SY and CC) independently screened the titles and abstracts of search results to identify potentially eligible trials, and full texts of these studies were checked to determine whether they met our inclusion 
criteria. One author (SY) extracted the data from the included trials. If the data were incomplete in the text but may be extrapolated from the figure, we extracted them from the figure by using the WebPlotDigitizer Version 4.1 (Austin: Ankit Rohatgi, 2018). In studies which did not report the standard deviations for changes from baseline in continuous variables, we calculated a correlation coefficient from a study with detailed information and used it to impute the standard deviations using the following equation:

$S D_{\text {change }}=\sqrt{\left(S D_{\text {Baseline }}\right)^{2}+\left(S D_{\text {Endpoint }}\right)^{2}-2 \times r \times S D_{\text {Baseline }} \times S D_{\text {Endpoint }}}$, where $r$ represents the correlation coefficient [11]. Another author $(C C)$ verified these data.

One author (SY) assessed the risk of bias of included studies by using the Cochrane Collaboration's tool [11] and the other author (CC) confirmed the judgment. The following items were categorized as having high, low or unclear risk of bias: random sequence generation, allocation concealment, blinding of participants and personnel, blinding of outcome assessment, incomplete outcome data, selective reporting, and other biases which focusing on baseline imbalance [11]. As to reporting bias, if a RCT did not report data on AEs, we rated it at high risk of selective reporting bias.

We used the Review Manager Version 5.3 (Copenhagen: The Nordic Cochrane Centre, The Cochrane Collaboration,
2014) in conducting meta-analysis. The random-effects model was employed due to anticipated clinical heterogeneity. Continuous outcomes were expressed as mean difference (MD) or as standardized mean difference (SMD) if different scales had been used to measure the same outcome. The statistical heterogeneity was assessed by calculating the $\mathrm{I}^{2}$ statistic.

\section{Results}

\section{Characteristics of included studies}

The PRISMA study flow chart is illustrated in Fig. 1. Our search identified 419 articles after removing duplicates. Among them, 13 RCTs with 625 participants met our inclusion criteria and were included in this study [12-24]. The fish oil supplement was administered orally in the form of capsule or oil in 11 RCTs [12-14, 16-19, 21-24] and given intravenously as lipid emulsion in 2 RCTs $[15,20]$. Three RCTs used capsules containing a combination of fish oil and evening primrose oil [21, 23, 24]. Five of the 13 included RCTs reported benefits of fish oil supplement in treating psoriasis $[12,14,15,17,20]$; the other eight RCTs, however, suggested fish oil supplement was not better than control treatment $[13,16,18,19,21-24]$. The characteristics of included RCTs are shown in Table 2. Three studies

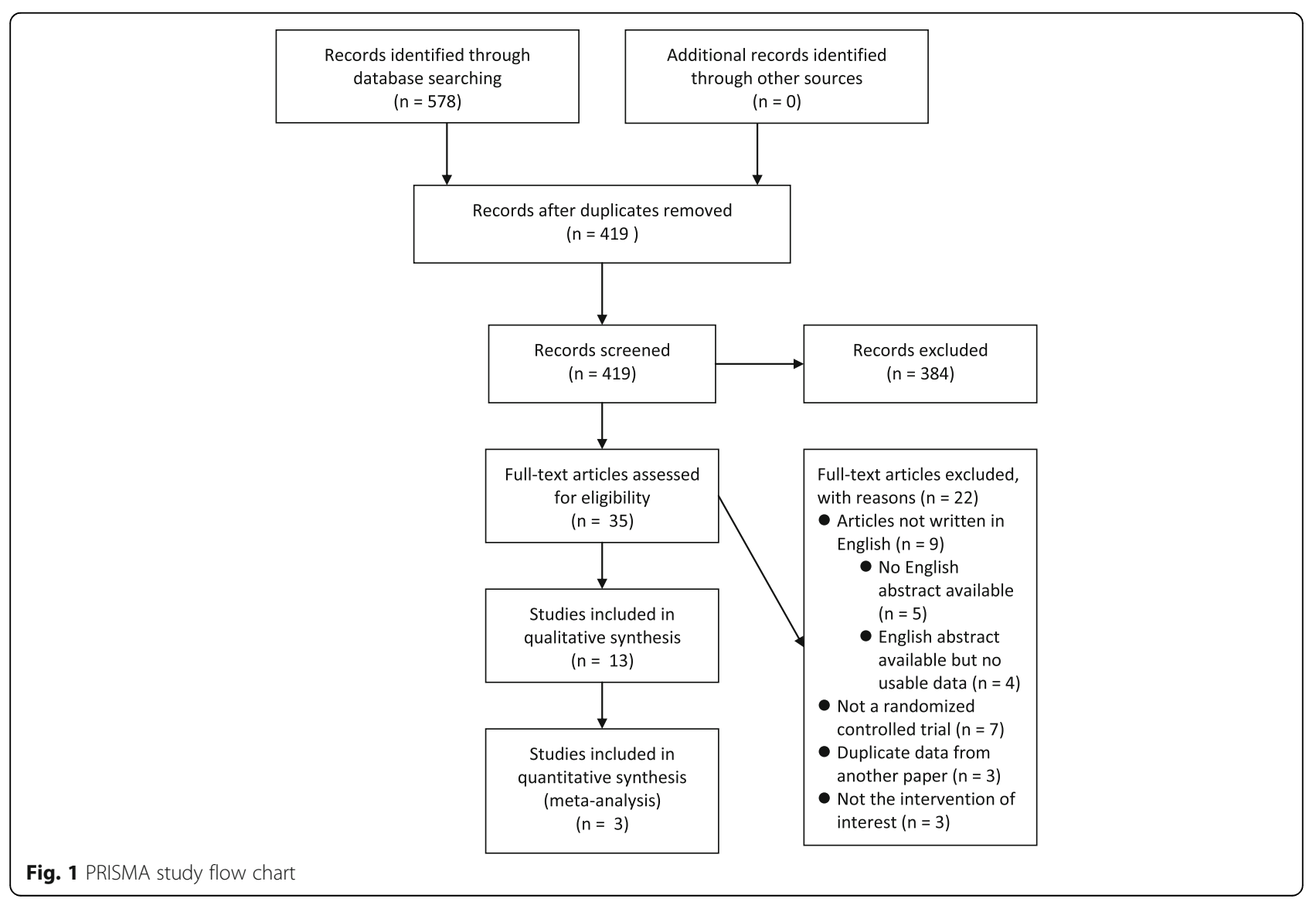




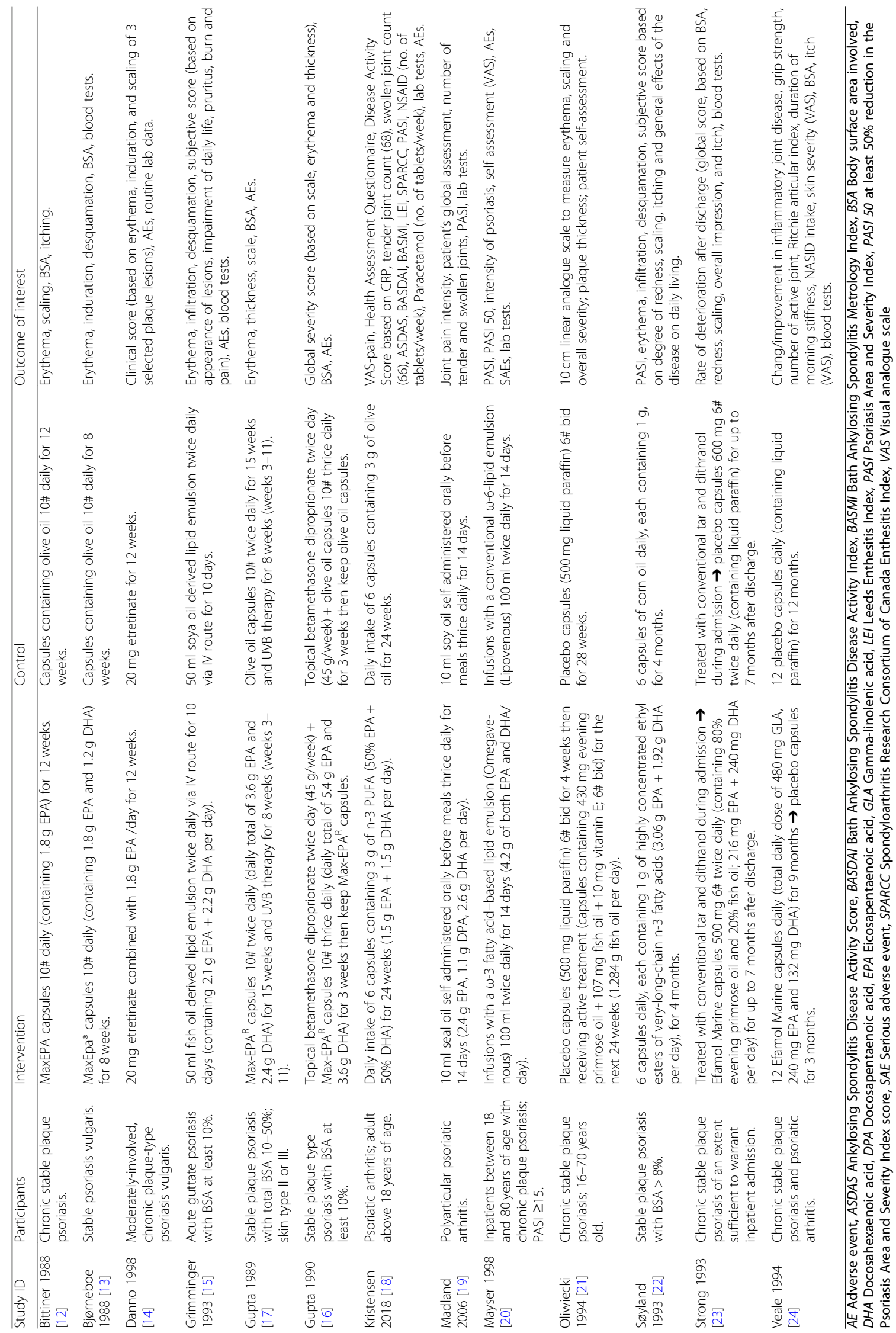


involving 337 participants provided usable data for metaanalysis $[18,20,22]$.

The risk of bias assessment of the included RCTs is illustrated in Fig. 2. Eleven out of the 13 included RCTs were published in 1980's and 1990's, and thus did not adequately describe the methods of random sequence generation, allocation concealment, and the methods of blinding for outcome assessment [12-17, 20-24]. Hence, these RCTs are rated as having unclear risk of bias on random sequence generation, allocation concealment, and blinding of outcome assessment.

\section{Effects of fish oil in treating psoriasis Psoriasis area and severity index score}

Three RCTs with 337 participants provided data for this outcome [18, 20, 22]. As illustrated in Fig. 3, the metaanalysis found fish oil did not produce significantly greater improvement in the PASI score than the control group (MD - 0.28; $95 \%$ confidence interval-1.74 to 1.19). The statistical heterogeneity across the included RCTs was significant $\left(I^{2}=57 \%\right)$.

\section{Body surface area}

Three RCTs contributed data for this outcome [12, 13, 17]. Bittiner et al. [12] reported a trend towards improvement of BSA in the fish oil group without statistical significance after 12 weeks of intervention (treatment group: $-3.0 \%, n=11$; control group: + $0.2 \%, n=13)$. Gupta et al. [17] reported significant improvement of BSA in the group of fish oil with concomitant UVB phototherapy than in the control group (treatment group: $-19.0 \%, n=8$; control group: $+11 \%, n=10 ; P=0.0001)$. Bjørneboe et al. [13], however, reported no significant change of involved area during the trial in both the experimental group $(n=13)$ and the control group $(n=14)$.

\section{Erythema, scaling, and induration}

Six RCTs supplied data for these outcomes [12, 13, 15, 17, 21, 22]. Bittiner et al. [12] reported a significant improvement in the erythema $(P<0.05)$, but not scaling, in the fish oil group $(n=11)$ than in the control group $(n=$ 13). Grimminger et al. [15] found the scores of erythema, scaling, and induration in the treatment group $(n=9)$ all improved significantly as compared with those in the control group $(n=11)(P<0.05)$. Gupta et al. [17] also reported significantly better response in respect to the scores of erythema $(P=0.02)$, scaling $(P=0.008)$ and induration $(P=0.006)$ in the treatment group $(n=8)$ than in the control group $(n=10)$. The study conducted by Søyland et al. [22], however, demonstrated no significant differences in the scores of erythema, scaling and induration between the treatment group $(n=61)$ and control group $(n=62)$. Oliwiecki et al. [21] also reported no significant difference in the scores of erythema, scaling and infiltration between the active and placebotreated groups. Bjørneboe et al. [13] reported no significant change in the scores of erythema, scaling and induration during the trial in both the experimental group $(n=13)$ and the control group $(n=14)$.

\section{Pruritus}

Two RCTs provided data on pruritus [12, 21]. Bittiner et al. [12] assessed pruritus on a 0 to 5 scale by the participants and found a trend to improvement after 12 weeks' fish oil supplement when compared to the control group (treatment group: $-1.3, n=11$; control group: $-0.3, n=13)$. Oliwiecki et al. [21] reported no significant difference between the active and placebo groups in the score of pruritus assessed by using a $10-\mathrm{cm}$ linear analogue scale.

\section{Adverse events}

Nine RCTs provided data concerning this outcome (Table 3) [13-18, 20, 23, 24]. Only a few minor AEs such as mild gastrointestinal adverse effects were reported. In two RCTs where fish oil supplement was given via intravenous route $[15,20]$, a few participants reported irritations at the injection site. As for the routine laboratory tests, none of the parameters significantly changed during the experimental period [13, 15, 20,23, 24], except for elevated liver enzyme levels in the study of Danno et al. [14], which could be attributed to concurrent use of etretinate. Overall, there were no significant differences in the incidence of AEs between the fish oil supplement group and control group.

\section{Discussion}

PASI, which combines the area affected and the severity of the erythema, scaling and induration into a single score, is the most commonly used tool for the measurement of psoriasis severity and treatment response. This study demonstrates that fish oil supplement did not significantly reduce the severity of psoriasis when measured by the PASI score. The effect of fish oil on reducing psoriasis BSA coverage is inconclusive. The studies by Bittiner et al. [12] and Gupta et al. [17] reported benefits but that by Bjørneboe et al. [13] did not. These data could not be pooled due to insufficient data reporting and methodological heterogeneity. The small sample size of these included RCTs is another limitation. When examining the signs and symptoms of psoriasis, the current evidence also shows conflicting results on the improvement of erythema, scaling, induration, and pruritus. Fish oil supplement was found well-tolerated and no severe AEs had been observed.

Five of the included studies did not provide usable outcome data regarding the therapeutic effect for 


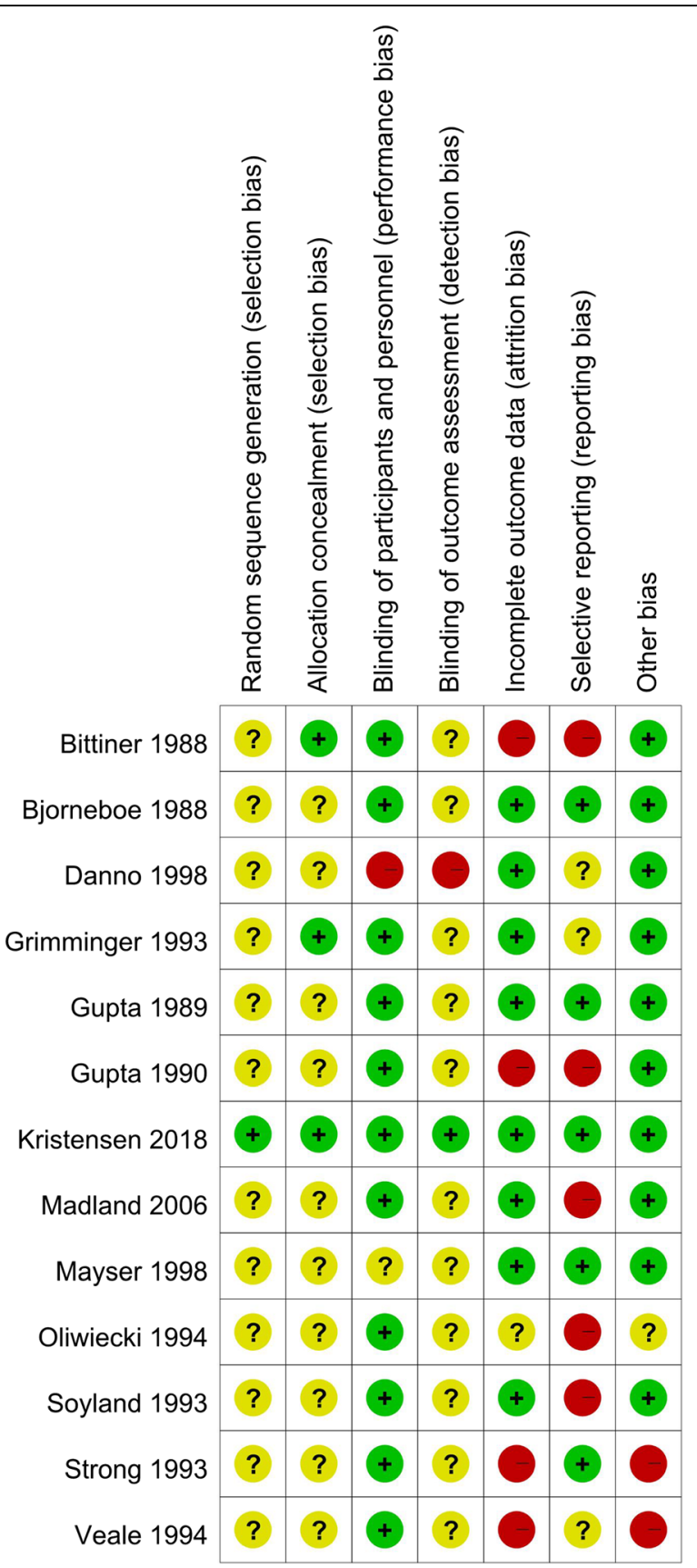

Fig. 2 Risk of bias assessment for included studies

psoriasis, and hence they were not incorporated into our data analysis [14, 16, 19, 23, 24]. Most of them (four out of the five studies) did not support the beneficial effect of fish oil on psoriasis [16, 19, 23, 24]. Danno et al. [14] used a clinical score based on erythema, induration, and scaling of 3 selected plaque lesions to evaluate the severity of psoriasis. They found the number of patients showing excellent improvement (namely, a decrease in the total score of $75 \%$ or more) was significantly greater in intervention group than that in control group. Gupta et al. [16] examined the effect of fish oil on maintaining the improvement achieved by topical steroid by comparing the time needed for psoriasis to worsen to pretherapy severity; no significant difference was found between the intervention and control group. Madland et al. [19] reported the severity of psoriasis was unchanged after treatment, but they did not provide data of PASI score. Strong et al. [23] studied the benefit of fish oil on maintaining the improvement obtained by inpatient treatment with conventional tar and dithranol by assessing 


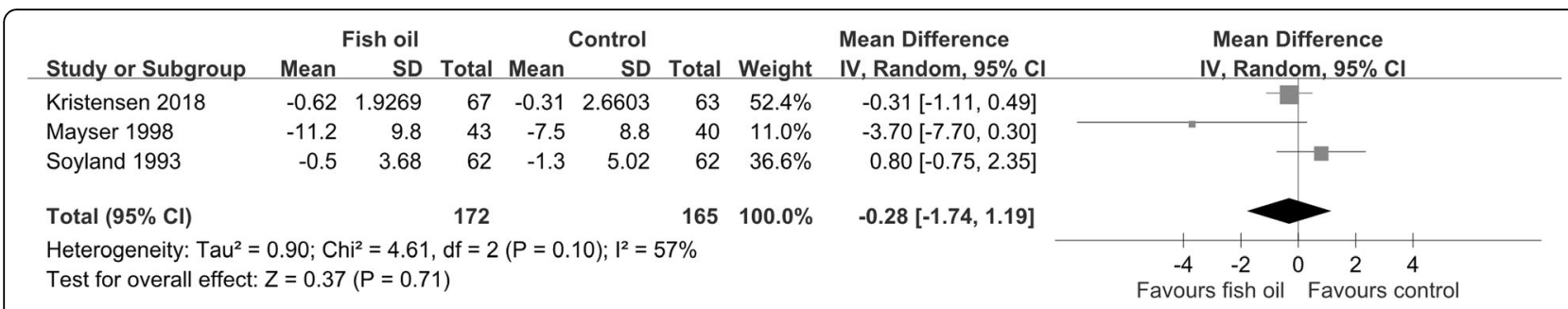

Fig. 3 Meta-analysis of efficacy of fish oil supplement in treating psoriasis assessed by Psoriasis Area and Severity Index score

the rate of deterioration after discharge; no significant difference was noted between the intervention and control group. Veale et al. [24] reported skin disease activity was unchanged in the intervention group but they did not provide data.

Fish oil supplement has been hypothesized to provide beneficial effects on psoriasis through its anti-inflammatory effects. Not surprisingly, there are also many studies focusing on the benefits of fish oil on other diseases with inflammatory properties for example arthritis. One systematic review on the effects of fish oil on arthritis concluded that fish oil might have a small favourable effect on arthralgia, but the evidence was of low quality [25]. Another popular issue is the protective effect of fish oil on cardiovascular disease (CVD) where inflammation plays a central role in its development and complications. Early studies have suggested the benefits of fish oil supplement on CVD. However, a recent meta-analysis involving 10 RCTs with 77,917 participants found no significant benefit of fish oil supplement in fatal or nonfatal coronary heart disease or any major vascular events [26]. Our study adds another piece of evidence that fish oil may have only limited benefit on certain diseases with inflammatory properties.

However, our study results should be interpreted cautiously for the following limitations. Firstly, most of the RCTs were done in 1980s and 1990s, and did not employ a standardized outcome assessment tool to measure the severity of psoriasis for example PASI score. Secondly, these early RCTs did not follow the Consolidated Standards of Reporting Trials (CONSORT) Statement [27] and the reporting of data was inadequate. Therefore, only a limited number of RCTs provided usable data for this study. Thirdly, we excluded non-English studies and thus might have missed relevant data.

There was a previous systematic review of 12 studies on the effects of omega-3 fatty acids on psoriasis [28]. They reported whether the use of omega- 3 fatty acids could benefit patients with psoriasis was inconclusive.

Table 3 Adverse events (AEs)

\begin{tabular}{|c|c|c|}
\hline Study ID & Intervention & Adverse events \\
\hline $\begin{array}{l}\text { Bjørneboe } \\
1988[13]\end{array}$ & Fish oil & $\begin{array}{l}\text { Routine lab: none of the parameters changed significantly during the trial (CBC, ESR, creatinine, } \\
\text { albumin, ALT, GGT, bleeding time, triglyceride, cholesterol). }\end{array}$ \\
\hline $\begin{array}{l}\text { Danno } 1998 \\
{[14]}\end{array}$ & Fish oil + Etretinate & $\begin{array}{l}\text { Cheilitis, dry mouth, dry eyes, desquamation of palms, folliculitis, gastric symptoms, and increased liver } \\
\text { enzymes. All were mild or tolerable. No significant difference in the incidence between intervention } \\
\text { and control groups. }\end{array}$ \\
\hline $\begin{array}{l}\text { Grimminger } \\
1993 \text { [15] }\end{array}$ & Fish oil (intravenous) & $\begin{array}{l}\text { No obvious side effect except for rare irritations at the site of peripheral intravenous route; routine lab: } \\
\text { not change substantially (ESR, CRP, cholesterol, triglyceride, BUN, ALT, GGT, amylase, lipase, coagulation } \\
\text { variables). }\end{array}$ \\
\hline $\begin{array}{l}\text { Gupta } 1989 \\
{[17]}\end{array}$ & $\begin{array}{l}\text { Fish oil + UVB } \\
\text { phototherapy }\end{array}$ & No side effect was reported in either group. \\
\hline $\begin{array}{l}\text { Gupta } 1990 \\
\text { [16] }\end{array}$ & $\begin{array}{l}\text { Fish oil + betamethasone } \\
\text { diproprionate cream }\end{array}$ & $\begin{array}{l}\text { An occasional fishy taste upon eructation in one patient on fish oil and one on olive oil therapy; } \\
\text { transient diarrhea at beginning of therapy in } 2 \text { patients on fish oil }\end{array}$ \\
\hline $\begin{array}{l}\text { Kristensen } \\
2018[18]\end{array}$ & Fish oil & Mild gastrointestinal adverse effects ( 9 in intervention group and 6 in control group) \\
\hline $\begin{array}{l}\text { Mayser } 1998 \\
{[20]}\end{array}$ & $\begin{array}{l}\text { Fish oil (intravenous) }+3 \% \\
\text { salicyclic acid }\end{array}$ & $\begin{array}{l}\text { Most frequently reported in intervention group: superficial thrombophlebitis; most frequently reported } \\
\text { in control group: superficial thrombophlebitis, pruritus, hypertriglyceridemia, and fever; no severe AEs; } \\
\text { routine lab: not substantially change (AST, ALT, Alk-P, creatinine, blood glucose, CBC/DC, total choles- } \\
\text { terol, triglyceride) }\end{array}$ \\
\hline $\begin{array}{l}\text { Strong } 1993 \\
{[23]}\end{array}$ & $\begin{array}{l}\text { Fish oil + evening primrose } \\
\text { oil }\end{array}$ & $\begin{array}{l}\text { Blood test: remained unchanged throughout the trial (CBC, urea, creatinine, total lipids, } \mathrm{HDL} \text { and } \mathrm{LDL} \text {, } \\
\text { cholesterol, triglyceride, electrolytes) }\end{array}$ \\
\hline $\begin{array}{l}\text { Veale } 1994 \\
\text { [24] }\end{array}$ & $\begin{array}{l}\text { Fish oil + evening primrose } \\
\text { oil }\end{array}$ & $\begin{array}{l}\text { No significant differences in lab indices including ESR, CRP, hemoglobin, urea, electrolytes, liver } \\
\text { enzymes }\end{array}$ \\
\hline
\end{tabular}


Our study differed from theirs in the following ways. Firstly, we added three more RCTs including a recent article published in 2018 [18]. Secondly, the previous review included open-label controlled observational studies and studies involving only dietary modification. By contrast, we excluded these low-quality studies and thus provide the best evidence regarding the effects of fish oil supplement in treating psoriasis. Thirdly, no metaanalysis was carried out in the previous review.

\section{Conclusions}

Our study found no consistent evidence supporting the use of fish oil supplement in treating psoriasis. For patients with psoriasis who hope to alleviate their symptoms from dietary changes, we could encourage them to lose weight through dietary control and exercise, for which there is stronger evidence on producing significant improvement in psoriasis severity $[29,30]$.

\section{Abbreviations}

AE: Adverse event; BSA: Body surface area; CVD: Cardiovascular disease; MD: Mean difference; PASI: Psoriasis Area and Severity Index;

RCT: Randomized controlled trial; SMD: Standardized mean difference

\section{Acknowledgements}

Not applicable.

\section{Authors' contributions}

CC: designed the study; SY and CC: conducted the search and screening; SY: extracted the data from the included trials; CC: verified the extracted data; SY and CC: analysed the data and performed the statistical analysis; SY: wrote the manuscript; CC: revised the manuscript; CC: had primary responsibility for final content. Both authors read and approved the final manuscript.

\section{Funding}

None.

\section{Availability of data and materials}

The datasets used and/or analysed during the current study are available from the corresponding author on reasonable request.

\section{Ethics approval and consent to participate}

Not applicable.

\section{Consent for publication}

Not applicable.

\section{Competing interests}

The authors declare that they have no competing interests.

\section{Author details}

'Department of Dermatology, Chang Gung Memorial Hospital, Keelung, Taiwan. ${ }^{2}$ Department of Dermatology, Chang Gung Memorial Hospital, Linkou, 5, Fuxing St, Guishan Dist, Taoyuan 33305, Taiwan. ${ }^{3}$ College of Medicine, Chang Gung University, Taoyuan, Taiwan.

Received: 4 September 2018 Accepted: 27 November 2019 Published online: 05 December 2019

\section{References}

1. Chi CC, Wang SH. Efficacy and cost-efficacy of biologic therapies for moderate to severe psoriasis: a meta-analysis and cost-efficacy analysis using the intention-to-treat principle. Biomed Res Int. 2014;2014:862851.

2. Kuo CM, Tung TH, Wang SH, Chi CC. Efficacy and safety of tofacitinib for moderate-to-severe plaque psoriasis: a systematic review and meta-analysis of randomized controlled trials. J Eur Acad Dermatol Venereol. 2018;32(3):355-62.
3. Yang TS, Chi CC, Wang SH, Lin JC, Lin KM. Cost-efficacy of biologic therapies for psoriatic arthritis from the perspective of the Taiwanese healthcare system. Int J Rheum Dis. 2016;19(10):1002-9.

4. Wang SH, Chi CC, Hu S. Cost-efficacy of biologic therapies for moderate to severe psoriasis from the perspective of the Taiwanese healthcare system. Int J Dermatol. 2014;53(9):1151-6.

5. Chi CC, Tung TH, Wang J, Lin YS, Chen YF, Hsu TK, Wang SH. Risk of uveitis among people with psoriasis: a nationwide cohort study. JAMA Ophthalmol. 2017;135(5):415-22.

6. Chi CC, Wang J, Chen YF, Wang SH, Chen FL, Tung TH. Risk of incident chronic kidney disease and end-stage renal disease in patients with psoriasis: a nationwide population-based cohort study. J Dermatol Sci. 2015;78(3):232-8.

7. Chi CC, Chen TH, Wang SH, Tung TH. Risk of suicidality in people with psoriasis: a systematic review and meta-analysis of cohort studies. Am J Clin Dermatol. 2017;18(5):621-7.

8. Calder PC. Omega-3 fatty acids and inflammatory processes. Nutrients. 2010; 2(3):355-74.

9. Millsop JW, Bhatia BK, Debbaneh M, Koo J, Liao W. Diet and psoriasis, part III: role of nutritional supplements. J Am Acad Dermatol. 2014;71(3):561-9.

10. Moher D, Liberati A, Tetzlaff J, Altman DG, Group P. Preferred reporting items for systematic reviews and meta-analyses: the PRISMA statement. PLoS Med. 2009;6(7):e1000097.

11. Higgins JP, Green S. Cochrane handbook for systematic reviews of interventions. Chichester: Wiley; 2011.

12. Bittiner S, Tucker W, Cartwright I, Bleehen S. A double-blind, randomised, placebo-controlled trial of fish oil in psoriasis. Lancet. 1988; (8582):378-80.

13. Bjørneboe A, Smith A, Bjørneboe G, Thune P, Drevon C. Effect of dietary supplementation with $\mathrm{n}-3$ fatty acids on clinical manifestations of psoriasis. Br J Dermatol. 1988;1 18(1):77-83.

14. Danno K, Sugie N. Combination therapy with low-dose etretinate and eicosapentaenoic acid for psoriasis vulgaris. J Dermatol. 1998;25(11):703-5.

15. Grimminger F, Mayser P, Papavassilis C, Thomas M, Schlotzer E, Heuer K, Führer D, Hinsch K, Walmrath D, Schill W. A double-blind, randomized, placebocontrolled trial of $\mathrm{n}-3$ fatty acid based lipid infusion in acute, extended guttate psoriasis. Rapid improvement of clinical manifestations and changes in neutrophil leukotriene profile. Clin Investig. 1993;71(8):634-43.

16. Gupta A, Ellis C, Goldfarb M, Hamilton T, Voorhees J. The role of fish oil in psoriasis. A randomized, double-blind, placebo-controlled study to evaluate the effect of fish oil and topical corticosteroid therapy in psoriasis. Int J Dermatol. 1990;29(8):591-5.

17. Gupta A, Ellis C, Tellner D, Anderson T, Voorhees J. Double-blind, placebocontrolled study to evaluate the efficacy of fish oil and low-dose UVB in the treatment of psoriasis. Br J Dermatol. 1989;120(6):801-7.

18. Kristensen S, Schmidt EB, Schlemmer A, Rasmussen C, Johansen MB, Christensen JH. Beneficial effect of $\mathrm{n}-3$ polyunsaturated fatty acids on inflammation and analgesic use in psoriatic arthritis: a randomized, double blind, placebo-controlled trial. Scand J Rheumatol. 2018;47(1):27-36.

19. Madland TM, Bjorkkjaer T, Brunborg LA, Froyland L, Berstad A, Brun JG. Subjective improvement in patients with psoriatic arthritis after short-term oral treatment with seal oil. A pilot study with double blind comparison to soy oil. J Rheumatol. 2006;33(2):307-10.

20. Mayser P, Mrowietz U, Arenberger P, Bartak P, Buchvald J, Christophers E, Jablonska S, Salmhofer W, Schill WB, Kramer HJ, et al. Omega-3 fatty acidbased lipid infusion in patients with chronic plaque psoriasis: results of a double-blind, randomized, placebo-controlled, multicenter trial. J Am Acad Dermatol. 1998;38(4):539-47.

21. Oliwiecki S, Burton J. Evening primrose oil and marine oil in the treatment of psoriasis. Clin Exp Dermatol. 1994;19(2):127-9.

22. Søyland E, Funk J, Rajka G, Sandberg M, Thune P, Rustad L, Helland S, Middelfart $\mathrm{K}$, Odu S, Falk E. Effect of dietary supplementation with very-long-chain n-3 fatty acids in patients with psoriasis. N Engl J Med. 1993;328(25):1812-6.

23. Strong A, Hamill E. The effect of combined fish oil and evening primrose oil (Efamol marine) on the remission phase of psoriasis: a 7-month double-blind randomized placebo-controlled trial. J Dermatolog Treat. 1993;4(1):33-6.

24. Veale D, Torley H, Richards I, O'Dowd A, Fitzsimons C, Belch J, Sturrock R. A double-blind placebo controlled trial of Efamol marine on skin and joint symptoms of psoriatic arthritis. Br J Rheumatol. 1994;33(10):954-8.

25. Senftleber NK, Nielsen SM, Andersen JR, Bliddal H, Tarp S, Lauritzen L, Furst DE, Suarez-Almazor ME, Lyddiatt A, Christensen R. Marine oil supplements for arthritis pain: a systematic review and meta-analysis of randomized trials. Nutrients. 2017;9(1):42. 
26. Aung T, Halsey J, Kromhout D, Gerstein HC, Marchioli R, Tavazzi L, Geleijnse JM, Rauch B, Ness A, Galan P. Associations of Omega-3 fatty acid supplement use with cardiovascular disease risks: meta-analysis of 10 trials involving 77917 individuals. JAMA Cardiol. 2018;3(3):225-34.

27. Schulz KF, Altman DG, Moher D. CONSORT 2010 statement: updated guidelines for reporting parallel group randomised trials. BMC Med. 2010; 8(1):18.

28. Upala S, Yong WC, Theparee T, Sanguankeo A. Effect of omega-3 fatty acids on disease severity in patients with psoriasis: a systematic review. Int J Rheum Dis. 2017;20(4):442-50.

29. Naldi L, Conti A, Cazzaniga S, Patrizi A, Pazzaglia M, Lanzoni A, Veneziano L, Pellacani G. Diet and physical exercise in psoriasis: a randomized controlled trial. Br J Dermatol. 2014;170(3):634-42.

30. Ko SH, Chi CC, Yeh ML, Wang SH, Tsai YS, Hsu MY. Lifestyle changes for treating psoriasis. Cochrane Database Syst Rev. 2019;7:CD011972. https://doi. org/10.1002/14651858.CD011972.pub2.

\section{Publisher's Note}

Springer Nature remains neutral with regard to jurisdictional claims in published maps and institutional affiliations.

Ready to submit your research? Choose BMC and benefit from:

- fast, convenient online submission

- thorough peer review by experienced researchers in your field

- rapid publication on acceptance

- support for research data, including large and complex data types

- gold Open Access which fosters wider collaboration and increased citations

- maximum visibility for your research: over $100 \mathrm{M}$ website views per year

At BMC, research is always in progress.

Learn more biomedcentral.com/submissions 